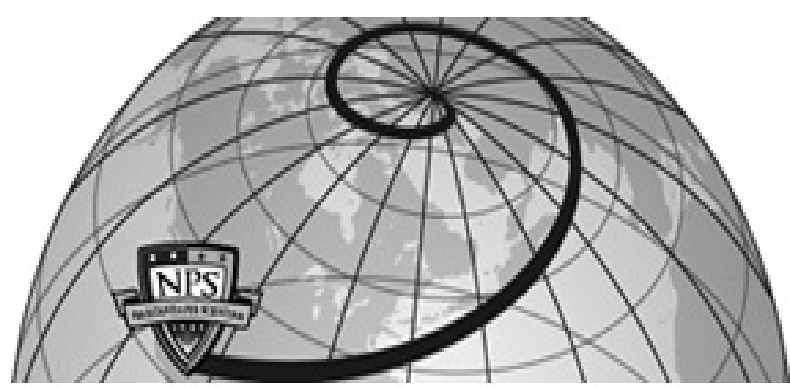

Calhoun: The NPS Institutional Archive DSpace Repository

The role of the halted baroclinic mode at the central equatorial Pacific in El Nino event

Sun, J.I.; Qinyu, Liu; Chu, Peter C.

Sun, J.I., P.C. Chu, and Q. Liu, 2006: The role of the halted baroclinic mode at the central equatorial Pacific in El Nino event (paper download). Advances in Atmospheric Sciences, Vol. 23, No. 1, 2005. pp. 45-53.

http://hdl.handle.net/10945/36190

This publication is a work of the U.S. Government as defined in Title 17, United States Code, Section 101. Copyright protection is not available for this work in the United States.

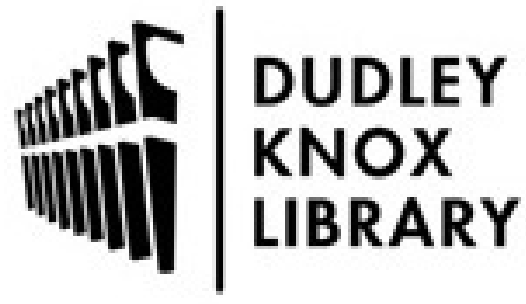

http://www.nps.edu/library
Calhoun is the Naval Postgraduate School's public access digital repository for research materials and institutional publications created by the NPS community. Calhoun is named for Professor of Mathematics Guy K. Calhoun, NPS's first appointed -- and published -- scholarly author.

Dudley Knox Library / Naval Postgraduate School 411 Dyer Road / 1 University Circle Monterey, California USA 93943 


\title{
The Role of the Halted Baroclinic Mode at the Central Equatorial Pacific in El Niño Event
}

\author{
SUN Jilin*1 (孙即霖), Peter CHU², and LIU Qinyu ${ }^{1}$ (刘秦玉) \\ ${ }^{1}$ Physical Oceanography Laboratory and Ocean-Atmosphere Interaction and Climate Laboratory, \\ Ocean University of China, Qingdao 266003 \\ ${ }^{2}$ Department of Oceanography, Naval Postgraduate School, Monterey, U.S.A.
}

(Received 1 March 2005; revised 27 July 2005)

\begin{abstract}
The role of halted "baroclinic modes" in the central equatorial Pacific is analyzed. It is found that dominant anomaly signals corresponding to "baroclinic modes" occur in the upper layer of the equatorial Pacific, in a two-and-a-half layer oceanic model, in assimilated results of a simple OGCM and in the ADCP observation of TAO. A second "baroclinic mode" is halted in the central equatorial Pacific corresponding to a positive SST anomaly while the first "baroclinic mode" propagates eastwards in the eastern equatorial Pacific. The role of the halted second "baroclinic mode" in the central equatorial Pacific is explained by a staged ocean-atmosphere interaction mechanism in the formation of El Niño: the westerly bursts in boreal winter over the western equatorial Pacific generate the halted second "baroclinic mode" in the central equatorial Pacific, leading to the increase of heat content and temperature in the upper layer of the central Pacific which induces the shift of convection from over the western equatorial Pacific to the central equatorial Pacific; another wider, westerly anomaly burst is induced over the western region of convection above the central equatorial Pacific and the westerly anomaly burst generates the first "baroclinic mode" propagating to the eastern equatorial Pacific, resulting in a warm event in the eastern equatorial Pacific. The mechanism presented in this paper reveals that the central equatorial Pacific is a key region in detecting the possibility of ENSO and, by analyzing TAO observation data of ocean currents and temperature in the central equatorial Pacific, in predicting the coming of an El Niño several months ahead.
\end{abstract}

Key words: halted baroclinic mode, central equatorial Pacific, staged atmosphere-ocean interaction mechanism, El Niño

\section{Introduction}

The gravest baroclinic waves have been shown to play important roles in the ocean adjustment (Philander, 1990). With the lateral boundary effect considered and coupled to atmosphere, the gravest oceanic baroclinic waves have been successfully applied in explaining the dynamics of the ENSO (El Niño/Southern Oscillation) event. ENSO phenomena have been studied worldwide for over a decade, and much progress has been made in realizing its mechanism and sometimes in giving a successful prediction. Under the frame of large-scale atmosphere and ocean interaction, theories and hypotheses have been presented to explain the development and quasi-cycle of the ENSO event (e.g., Hirst, 1986; Battisti, 1988). Typical ENSO events summarized by Rassmuson and Carpenter (1982) were well simulated in some air-sea coupled models (e.g., Zebiak and Cane, 1987). The features of this kind of $\mathrm{El}$ Niño occurred in the coupled model, such as the westward displacement of the positive SST anomaly and the anomalous westerly response to the SST anomaly migration. Yet there are still some problems that need to be solved. For example, since 1982-1983, El Niño events always appear to have the characteristic of the positive SST anomaly moving eastward from the west of the Pacific basin to the east. Using an ocean GCM forced by the observed wind field, Philander (1983) better simulated the 1982-1983 El Niño event. Their simulations gave the impression that the El Nino was a forced event but no exact physical processes were given. Figures 1 and 2 are observed results from 1993 to 1995 and from 1996 to 1998 copied from the "Climate Diagnostics Bulletin".

*E-mail: sunjilin@mail.ouc.edu.cn 


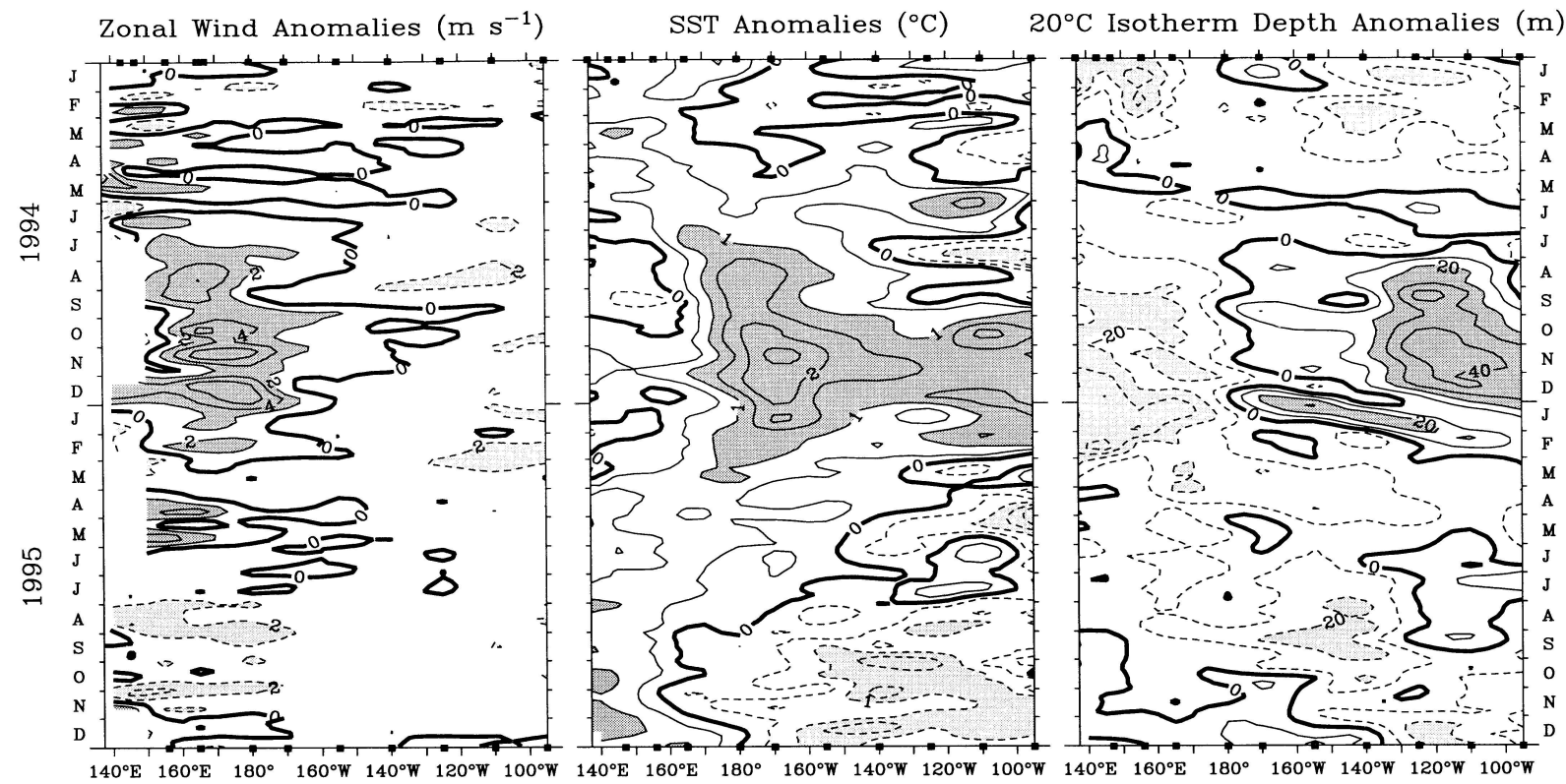

Fig. 1. (a) Zonal wind anomaly, (b) SST anomaly and (c) $20^{\circ} \mathrm{C}$ isotherm depth anomaly from May 1993 to April 1995 (taken from Climate Diagnostics Bulletin).
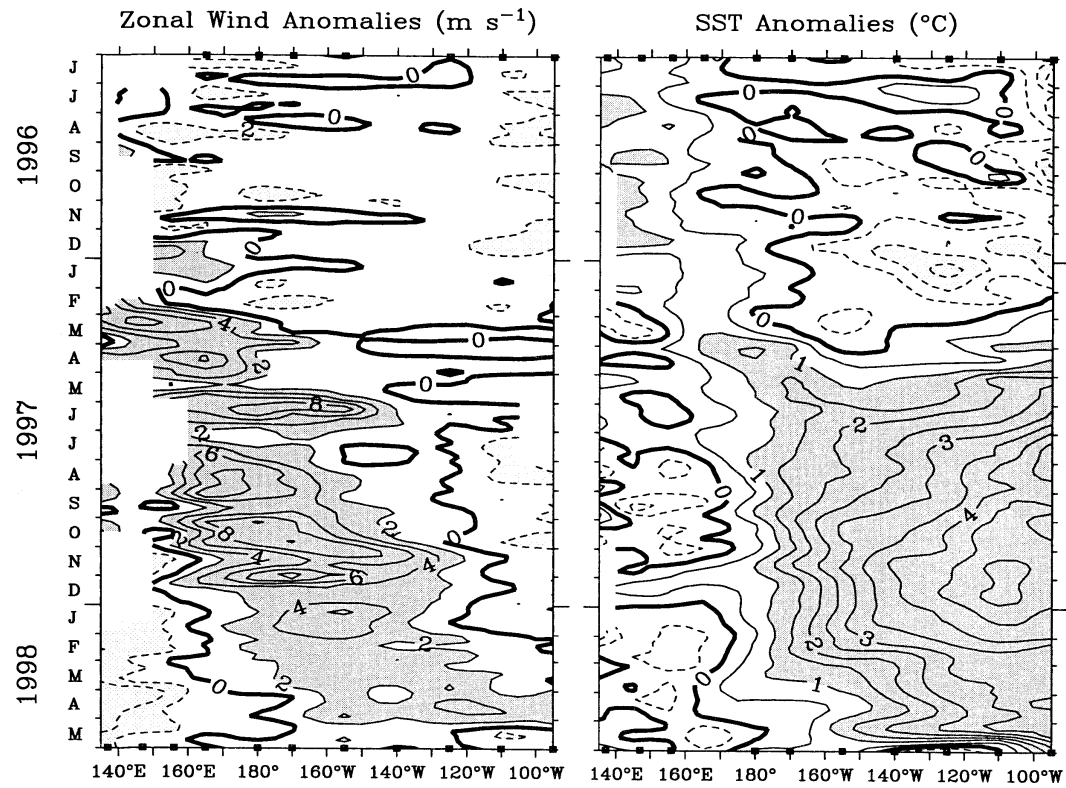

$20^{\circ} \mathrm{C}$ Isotherm Depth Anomalies (m)

Fig. 2. (a) Zonal wind anomaly, (b) SST anomaly and (c) $20^{\circ} \mathrm{C}$ isotherm depth anomaly from August 1996 to July 1998 (taken from NOAA/National Weather Service).

It can be seen from these figures that, before the El Niño event develops, positive SST anomalies first occur in the central equatorial Pacific and then spread eastwards. In the atmosphere, before the central Pacific warms, westerly anomalies spread over the equatorial western Pacific. The timescale for the westerly anomaly is intraseasonal. Lau and Chan (1986) presented a hypothesis that the intraseasonal timescale oscillations in the tropical atmosphere might be a trig- ger for the El Niño event. In studying the 1996/1997 ENSO event, McPhaden et al. (1999) and van Oldenborgh (2000) found that the onset of the El Niño was linked to eastward propagating equatorial Kelvin waves forced by intraseasonal atmospheric oscillations. Since the intraseasonal timescale westerly burst happens many times over the equatorial Pacific each year, what mechanisms are there in the connections between the atmospheric intraseasonal westerly wind burst and 


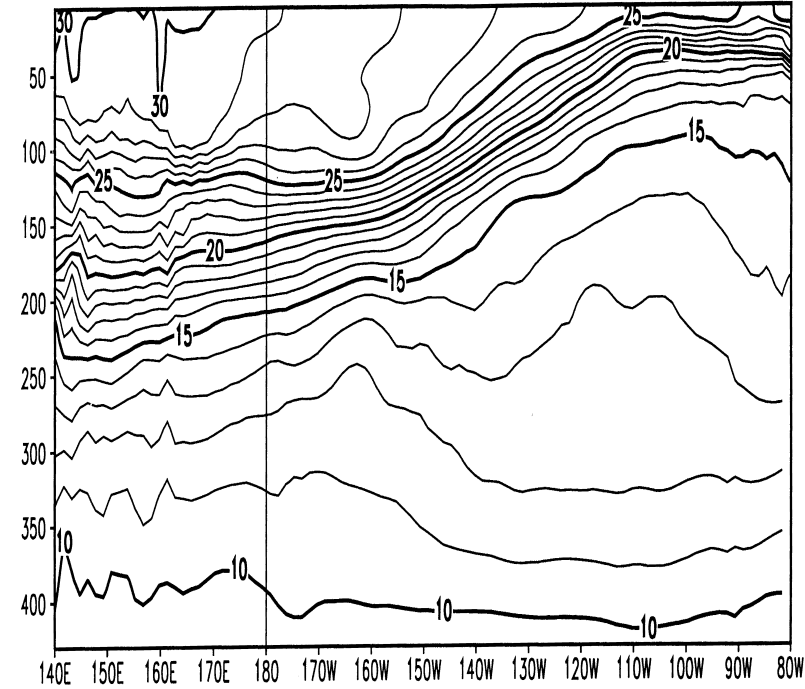

Fig. 3. Longitude-depth cross section of long-time mean water temperature in April along the equator made by Kessler (taken from http://www.pmel.noaa.gov/tao/clim/ clim.html).

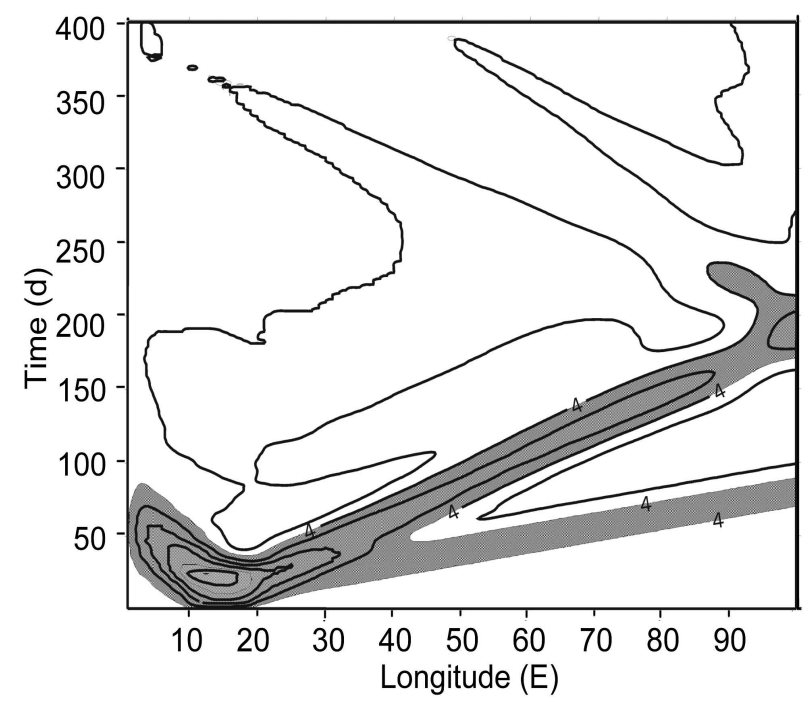

Fig. 4. Longitude-time cross section of westerly burst perturbed zonal currents of two baroclinic modes in a twoand-a-half layer tropical ocean model when the upper layer is initially set at $75 \mathrm{~m}$ and the second layer set at $175 \mathrm{~m}$ (upper layer, positive values are shaded. units: $\mathrm{cm} \mathrm{s}^{-1}$ ).

the occurrence of the El Niño event? Sun at al (1997), Sun and Li (1998) has analyzed the 1994 El Niño event and found that the stationary phenomena of the positive SST anomaly and sea level anomaly in the central equatorial Pacific may be closely related with the El Niño event. A hypothesis of a staged atmosphereocean interaction mechanism was presented in their study. In this paper, by analyzing the oceanic response results from a two-and-a-half layer tropical ocean model and assimilated results from an OGCM, we found that the halting of the second baroclinic mode in the central equatorial Pacific really caused the increase of the SST anomaly in the boreal winter in the central equatorial Pacific. The next westerly may be connected with the seasonal cycle because, in the boreal spring, when the ITCZ is at its position near the equator, convection will be more favored over the warmer water of the central equatorial Pacific, thus leading to another intraseasonal westerly burst over the western-central equatorial Pacific. The second westerly burst will generate more powerful baroclinic mode propagation to the eastern equatorial $\mathrm{Pa}$ cific, leading to an El Niño event. Thus, in the tropical atmosphere-ocean system, staged interaction processes are likely to exist.

\section{The halted mode in a two-and-a-half layer model and the effect of background wind}

Dewitte et al. (1999) studied the linear vertical modes near the equator using an OGCM and found that the characteristics of the vertical modes vary more in space than in time. The first two modes contribute with comparable amplitudes but with different spatial distributions in the equatorial wave-guide. Boulanger (2001) investigated how well an oceanic model whose dynamics are based on long equatorial waves can simulate the large-scale surface zonal current variability and validated an ocean linear model, which can be run with two or three layers, against several sets of observations in the Pacific Ocean. Figure 3 is a longitudedepth section of long-term mean water temperature

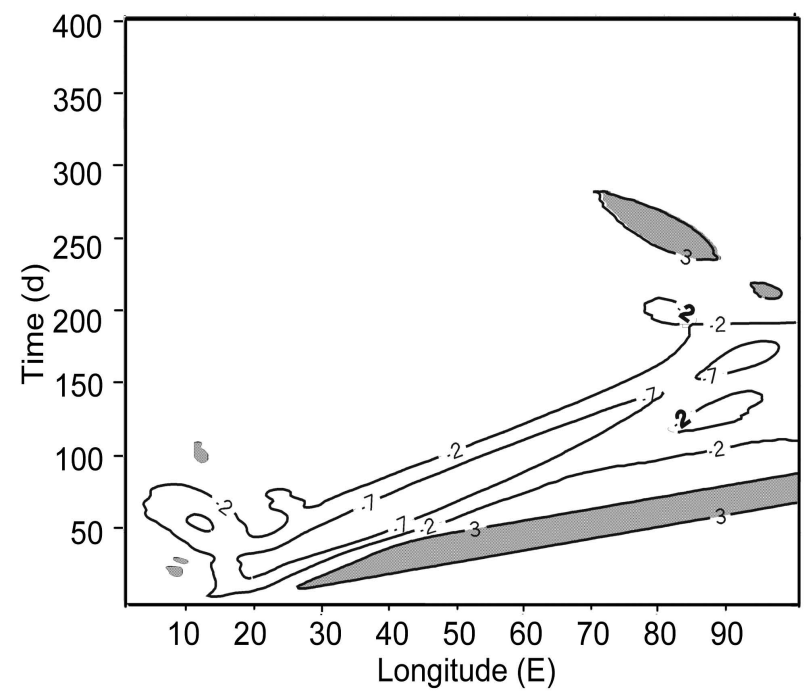

Fig. 5. Longitude-time cross section of westerly burst perturbed zonal currents of two baroclinic modes in a twoand-a-half layer tropical ocean model when the upper layer is initially set at $75 \mathrm{~m}$ and the second layer set at $175 \mathrm{~m}$ (lower layer, positive values are shaded. units: $\mathrm{cm} \mathrm{s}^{-1}$ ). 


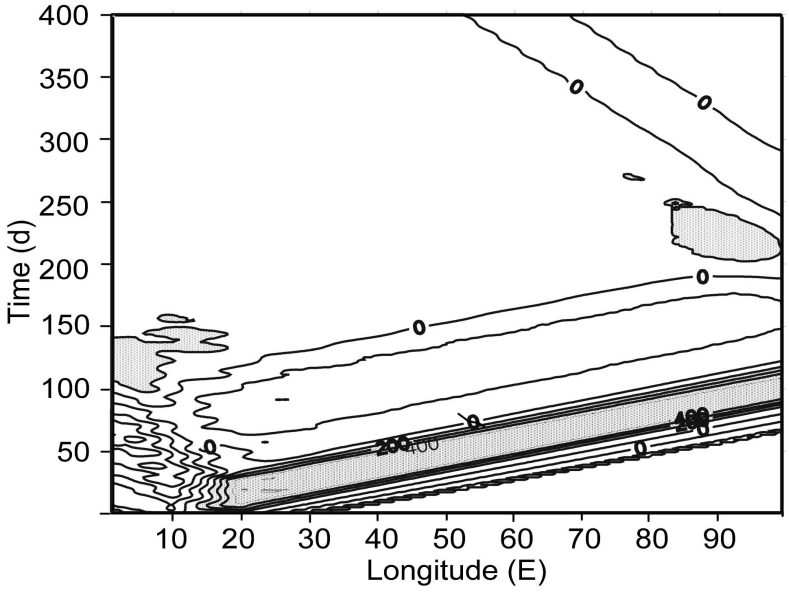

Fig. 6. Longitude-time cross section of westerly burst perturbed zonal currents mode in a one-and-a-half layer tropical ocean model when the upper layer is initially set at $150 \mathrm{~m}$ (positive values are shaded. units: $\mathrm{cm} \mathrm{s}^{-1}$ ).

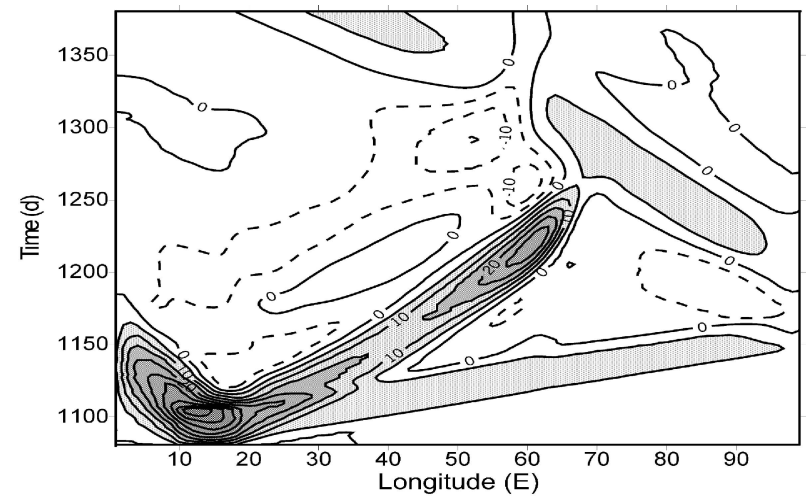

Fig. 7. Longitude-time cross section of westerly burst perturbed zonal currents of two baroclinic modes in a two-and-a-half layer tropical ocean model starting from a nearly equilibrium state of 1080 days of integration (upper layer, positive values are shaded. units: $\mathrm{cm} \mathrm{s}^{-1}$ ).

at May of 2002 along the Eqator. If we consider the mixed layer as the upper layer, the thermocline layer as the second layer and the layers below the thermocline as the lower layer, in the simplest point of view, the tropical ocean can be divided into three layers in the western tropical basin and two layers in the eastern tropical basin.

The oceanic part of the model in the atmosphereocean system presented by Zebiak and Cane (1987) is actually two layers. Only one baroclinic mode existed in their model. The model used in this paper is a twoand-a-half layer model initially created by McCreary and $\mathrm{Yu}$ (1992). It can be easily reduced to a one-anda-half layer model by a simple change of parameter. Some modifications of coefficients and damping terms were made in this study in getting the results of the current response to a 25-day westerly burst in Figs. 4 and 5. Wind forcing was over an area of $10^{\circ}$ longitude (from $10^{\circ} \mathrm{E}$ to $190^{\circ} \mathrm{E}$ ) and $6^{\circ}$ latitude symmetrically across the equator initially starting with calm conditions. It can be seen from the figures that the intraseasonal westerly burst can generate two baroclinic modes in this layered model. Both modes propagate eastwards but the second one propagates much slower than the first mode. The differences between Figs. 4 and 5 are apprent. The current induced by the second baroclinic mode has an opposite direction in the upper layer compared to the second layer. When the model is reduced to one and a half layers (Fig. 6), there is only one baroclinic mode. Note that when the depth of the active layer is taken as the typical depth of the thermocline in the eastern part as in Fig. 3, the propagation speed in the model ocean is similar to the speed of the $20^{\circ} \mathrm{C}$ isotherm depth anomaly signal in the eastern equatorial Pacific in Figs. 1 and 2. In the experiment to extract these baroclinic waves from the background, the model ocean was first integrated for 1080 days to reach the equilibrium state forced by a meridional uniform westward wind field (McCreary and Yu, 1992 ) with maximum stress at $61^{\circ} \mathrm{N}$ (the grid in the experiment is $\left.1^{\circ} \times 1^{\circ}\right)$. Then, an anomalous patch of westerly wind was added for 25 days to the region from grids 10 to 19 in a zonal direction symmetrically about the equator for 6 grids wide (only the wind anomaly is used in creating Figs. 4 and 5). It is pronounced in Fig. 7 that the second baroclinic mode was halted in the central region of the model basin. Corresponding to the ceasing of the propagation of the wave, the amplitude of the halted mode was increased and the

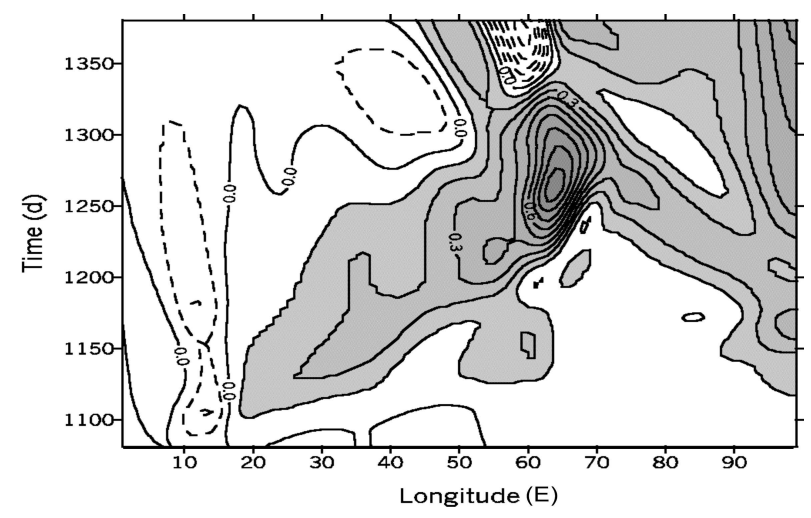

Fig. 8. Longitude-time cross section of westerly burst perturbed temperature anomaly of two baroclinic modes in a two-and-a-half layer tropical ocean model starting from a nearly equilibrium state of 1080 days of integration (upper layer, positive values are shaded. units: ${ }^{\circ} \mathrm{C}$ ). 


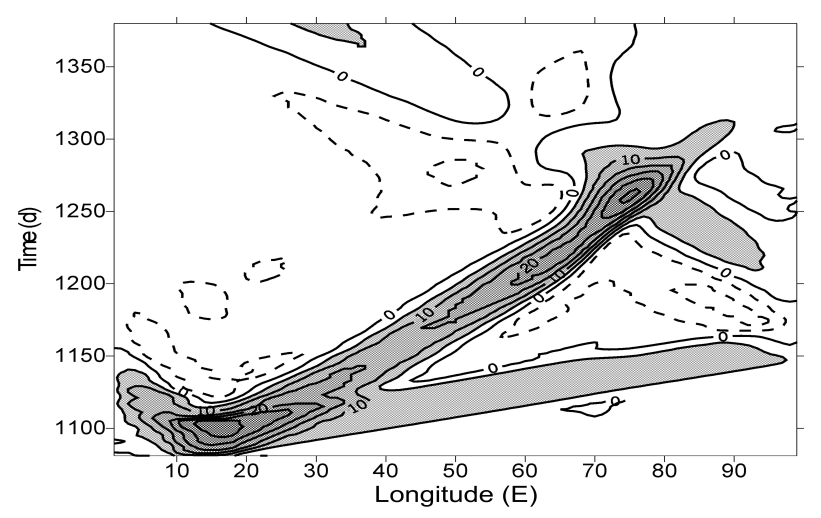

Fig. 9. Longitude-time cross section of westerly burst perturbed zonal currents of two baroclinic modes in a two-and-a-half layer tropical ocean model starting from a nearly equilibrium state of 1080 days of integration [(the background wind stress is 0.85 times stronger than in Fig. 7) upper layer, positive values are shaded. unit: $\mathrm{cm} \mathrm{s}^{-1}$ ].

temperature of the upper layer also increased by nearly $1^{\circ} \mathrm{C}$ at its maximum (Fig. 8).

When the strength of the background wind was reduced to $85 \%$ of that used in generating Fig. 7 , the location of the baroclinic mode halting was moved to the region near the eastern boundary (Fig. 9). This reveals that, in the ocean adjustment, except for the first Kelvin baroclinic mode, the other higher vertical Kelvin mode can be much affected by the background of the climate. By examining the model experiments, we found that the halted second baroclinic mode in the model results also has the characteristics of a positive upper layer depth anomaly corresponding to the positive temperature anomaly.

In section 3 of this paper, we examine the assimilated results of vertically averaged SODA data to discuss the baroclinic modes.

\section{Analysis of assimilating data along the equa- torial Pacific}

Monthly data assimilated by a simple ocean data assimilation (SODA) analysis (Carton et al., 2000) were used to analyze the baroclinic modes. The grid interval in the dataset is $1^{\circ}$ in the zonal direction and variable in the meridional direction.

The anomalous current induced by the second baroclinic mode has two zero points in the vertical direction. In the upper layer, the current related with the second vertical mode is eastward while in the second layer (regarded as the vertical average of the thermocline) the direction is westward. In the vertical average, the time serials of anomalous currents, anomalous wind stress and water temperature near the surface were calculated (Figs. 10-12).
Figure 10 gives the vertically-averaged zonal current anomaly at $165^{\circ} \mathrm{E}$ and the near-surface temperature anomaly averaged from $170^{\circ} \mathrm{E}$ to $170^{\circ} \mathrm{W}$. The thick solid line is for the current anomaly in the upper $100 \mathrm{~m}$, the thin solid line for the current anomaly in the layer between depths of $100 \mathrm{~m}$ to $250 \mathrm{~m}$ and the dotted line for the average water temperature anomaly. It shows that, except in the years 1951, 1986/1987, 1992, in the previous boreal winter of an El Niño year, there was a current anomaly structure like the structure of the second baroclinic mode. Following with this type of signal, the positive SST anomaly in the vicinity of the data line is also increased.

It can also be seen from Fig. 10 that the second baroclinic signal is seasonally dependent because of the same characteristics in wind stress. Liu and Qin (1994) found that the energy of the intraseasonal timescale oscillation was stronger in the boreal winter over the western tropical Pacific before the El Niño event. From the study in this section, it is easy to realize how strongly the intraseasonal wind stress variation affects the El Niño event by examining the zonal current and SST anomalies in the central basin of the equatorial Pacific.

In Fig. 10, there are 15 years with such characteristics. These years do not include the El Niño years like 1951, 1986-87 or 1992, but include 1990, a year which seemed to be an El Niño year but turned out not to be. In almost all of these $14 \mathrm{El}$ Niño years, the central equatorial Pacific warming anomaly with the second baroclinic mode were several months (1-6 months) ahead of El Niño event.

Figure 11 gives the averaged current anomalies at $140^{\circ} \mathrm{W}$ in the upper layer above $50 \mathrm{~m}$, in the layers between $50 \mathrm{~m}$ and $200 \mathrm{~m}$, and in the layer below 200 $\mathrm{m}$. Unlike the structure at $165^{\circ} \mathrm{E}$, there is no structure such as the second baroclinic mode in the mixed layer and thermocline. Variations of current anomalies in the upper layer and the second layer are approximately in phase while the current anomaly in the lower layer is nearly always out of phase. Thus, at the location of $0^{\circ}, 140^{\circ} \mathrm{W}$, the signal appears to have the structure of the first baroclinic mode.

Figure 12 is similar to Fig. 10 except the wind stress averaged from $145^{\circ} \mathrm{E}$ to $165^{\circ} \mathrm{E}$ is replaced by the SST anomaly. The phase of the wind stress variation is a little ahead of the phase of the second baroclinic mode like signals during most El Niño years. The wind stress must be responsible for the occurrence of such signals. It is implied that the intraseasonal timescale westerly burst can generate the baroclinic mode anomaly in the central equatorial Pacific. A numerical study made by van Oldenborgh (2000) also obtained such a result in the 1996/1997 El Niño event. 


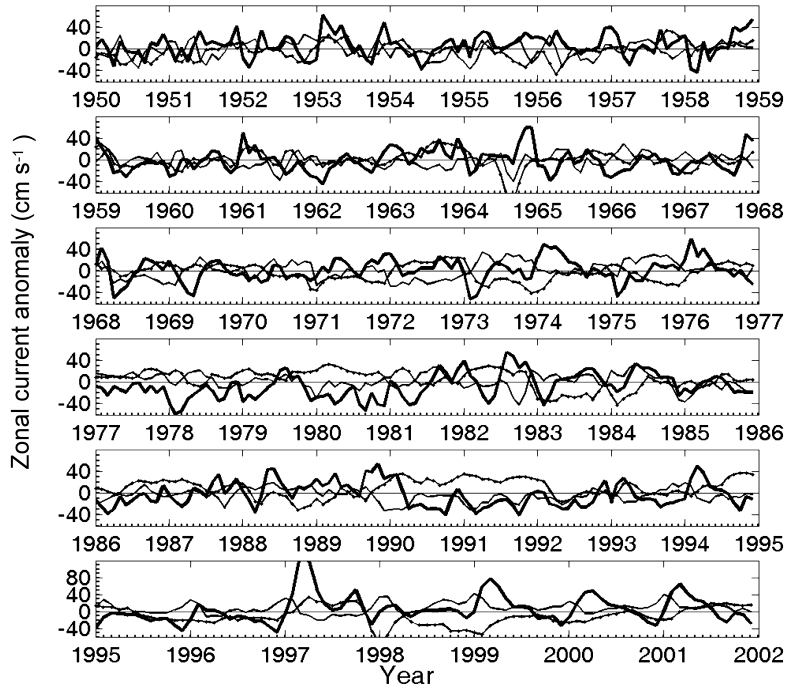

Fig. 10. Vertically-averaged zonal current anomaly at $165^{\circ} \mathrm{E}$ and near-surface temperature anomaly averaged from $170^{\circ} \mathrm{E}$ to $170^{\circ} \mathrm{W}$. The thick line is for the layer from the surface to a depth of $100 \mathrm{~m}$, the thin line for the layer between depths $100 \mathrm{~m}$ and $250 \mathrm{~m}$ and the dotted line for the temperature anomaly (values $\times 20$ ).

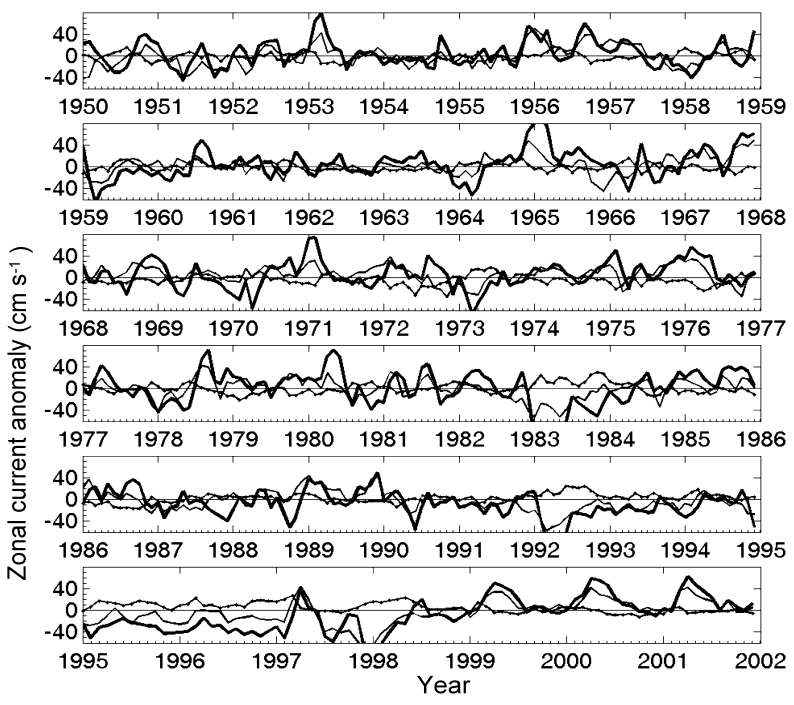

Fig. 11. Vertically-averaged zonal current anomaly at $140^{\circ} \mathrm{W}$. The thick line is for the layer from the surface to a depth of $50 \mathrm{~m}$, the thin line for the layer between depths $50 \mathrm{~m}$ to $200 \mathrm{~m}$ and the dotted line for the layer between depths $200 \mathrm{~m}$ and $400 \mathrm{~m}$.

The central equatorial Pacific may be a key region in the development of El Niño events. Boulanger (2001) found that the addition of a second baroclinic mode always improves the simulation of both the sea level and the surface currents in an OGCM, especially in the central western Pacific.

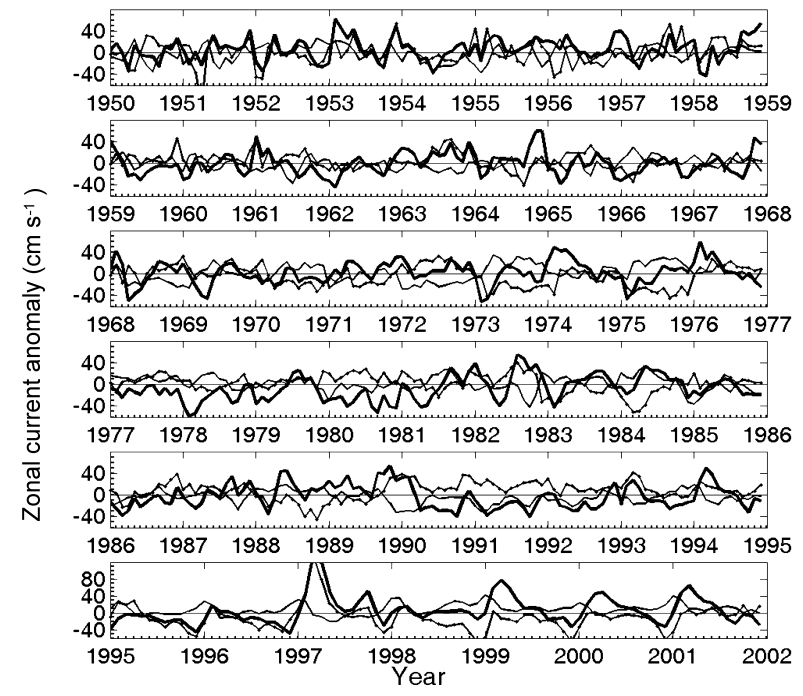

Fig. 12. Vertically-averaged zonal current anomaly at $165^{\circ} \mathrm{E}$ and sea surface wind stress anomaly averaged over $2^{\circ} \mathrm{S}$ to $2^{\circ} \mathrm{N}, 145^{\circ} \mathrm{E}$ to $165^{\circ} \mathrm{E}$. The thick line is for the layer from the surface to a depth of $100 \mathrm{~m}$, the thin line for the layer between depths $100 \mathrm{~m}$ and $250 \mathrm{~m}$ and the dotted line for the wind stress anomaly (values $\times 150$ ).

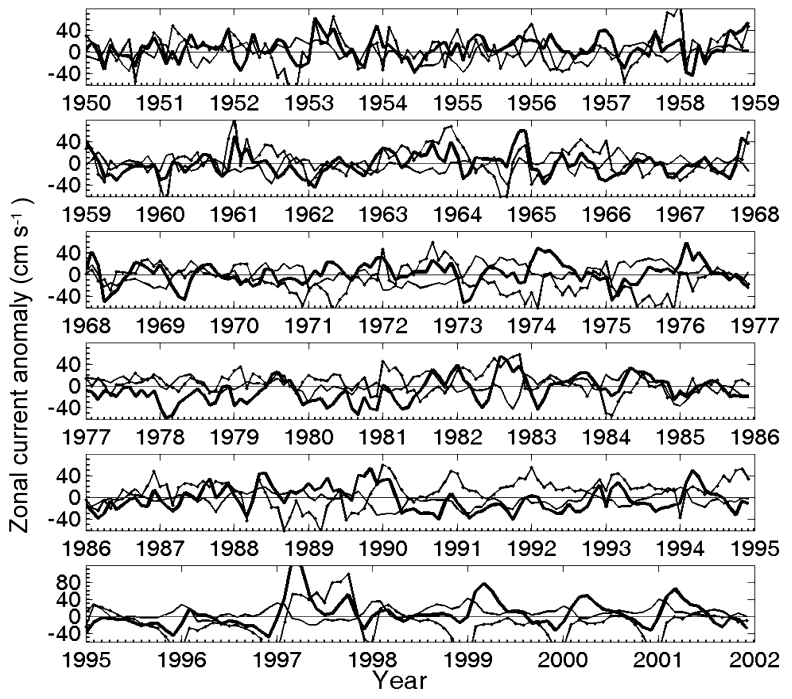

Fig. 13. Vertically-averaged zonal current anomaly at $165^{\circ} \mathrm{E}$ and sea surface wind stress anomaly averaged over $2^{\circ} \mathrm{S}$ to $2^{\circ} \mathrm{N}, 160^{\circ} \mathrm{E}$ to $180^{\circ} \mathrm{E}$. The thick line is for the layer from the surface to a depth of $100 \mathrm{~m}$, the thin line for the layer between depths $100 \mathrm{~m}$ and $250 \mathrm{~m}$ and the dotted line for the wind stress anomaly (values $\times 150$ ).

4. The effect of the second baroclinic mode signals on the wind stress anomaly over the western-central equatorial Pacific

When the regional averaged wind stress is taken 


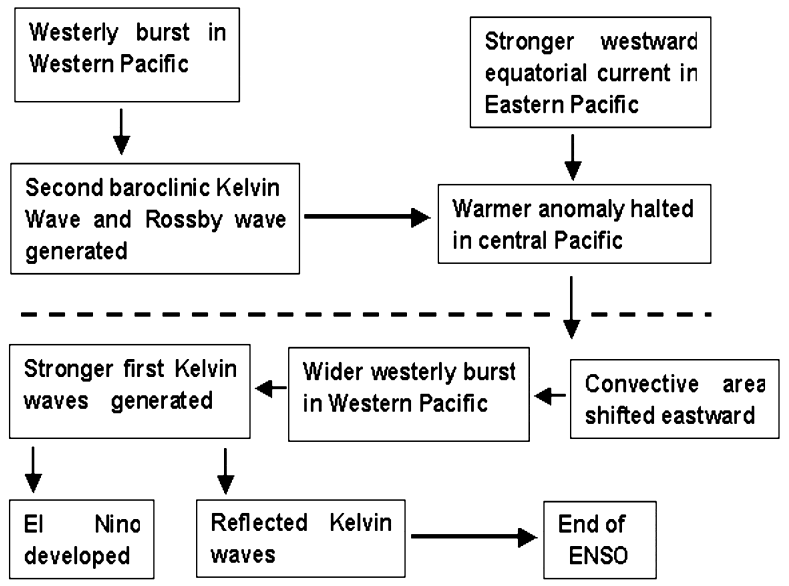

Fig. 14. A sketch of the staged atmosphere-ocean interaction related with the abnormal warming in the central equatorial Pacific. Above and below the dashed line are the first and second stages, respectively.

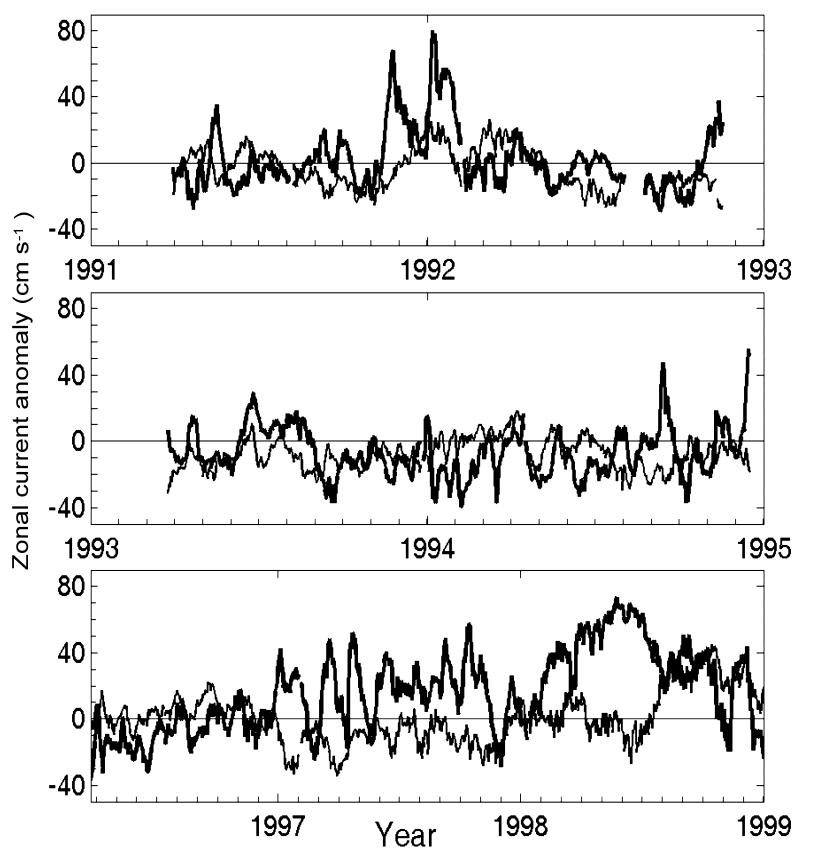

Fig. 15. Zonal current anomalies at $0^{\circ}, 165^{\circ} \mathrm{E}$ observed by TAO. The thick line is the result averaged in the upper $100 \mathrm{~m}$, and the thin line is the result averaged from $100 \mathrm{~m}$ to $250 \mathrm{~m}(1993-1999)$.

within $2^{\circ} \mathrm{S}$ to $2^{\circ} \mathrm{N}, 145^{\circ} \mathrm{E}$ to $165^{\circ} \mathrm{E}$, instead of $2^{\circ} \mathrm{S}$ to $2^{\circ} \mathrm{N}, 160^{\circ} \mathrm{E}$ to $180^{\circ} \mathrm{E}$, the phase of the wind stress anomaly is changed (Fig. 13). In most El Niño years, the anomalous signal of the oceanic baroclinic mode appears earlier than the increase of the wind stress during the boreal winter or spring. This is important. It had long been pointed out that the location of the ITCZ was close to the equator in the time leading up to an El Niño event. From Figs. 1, 2 and 8, the SST anomaly caused by the second baroclinic mode is around $1^{\circ} \mathrm{C}$, lasting 2 to 3 months, corresponding to the actual SST beyond $28^{\circ} \mathrm{C}$; the increased heating by warm water and the ITCZ jointly together may favor the shifting of the deep convective center from over the western tropical Pacific to the region near the date line, leading to the prevailing of the westerly anomaly over the west of the convective region. The mechanism discussed here is the atmosphere-ocean interaction, but it contains two different stages: the tropical ocean responds to the intraseasonal westerly first by a halted second baroclinic mode and then, with the help of the ITCZ, the tropical atmosphere responds to the increased heating in the central Pacific by a second westerly anomaly, the induced westerly in turn drives the ocean again, generating the first mode's propagation to the eastern basin of the equatorial Pacific.

Chen et al. (2001) studied the relation between the intraseasonal oscillation and ENSO, finding that the intraseasonal oscillation is closely related with the SST in the Niño-3 region. Sun et al. (1997) presented such a mechanism (Fig. 14), but the second stage was not proved and was examined without considering the role of the seasonal position of the ITCZ. The study in this paper completes the whole picture and proves that the scenario is possible.

\section{Second-baroclinic-mode signals in the TAO observation and as a simple prediction index of El Niño}

Figure 15 shows the zonal current anomaly observed by $\mathrm{ADCP}$ at $165^{\circ} \mathrm{E}$ on the equator. It is also obvious that at the beginning of the El Niño event, there were vertical structures like the second baroclinic mode being observed in the years 1993, 1994 and 1996. Thus the assimilated results are reliable.

In Fig. 6, there are more instances of the second baroclinic mode than in El Niño years. For instance, in the years of 1999, 2000 and 2001, there were second baroclinic modes in the currents but the spatiallyaveraged surface temperature anomaly around the date line was also below zero. This implies that processes with larger spatial and temporal scales may be other factors that need to be considered. Because the temperature in the equatorial region is more closely related with the meridional cell in the longer time scales than the second baroclinic mode, the interrelation between the halted mode and the meridional cell will be discussed in a later paper.

Since there is an ADCP current and temperature observation system in the tropical Pacific, it will be convenient to judge a coming El Niño by examining 

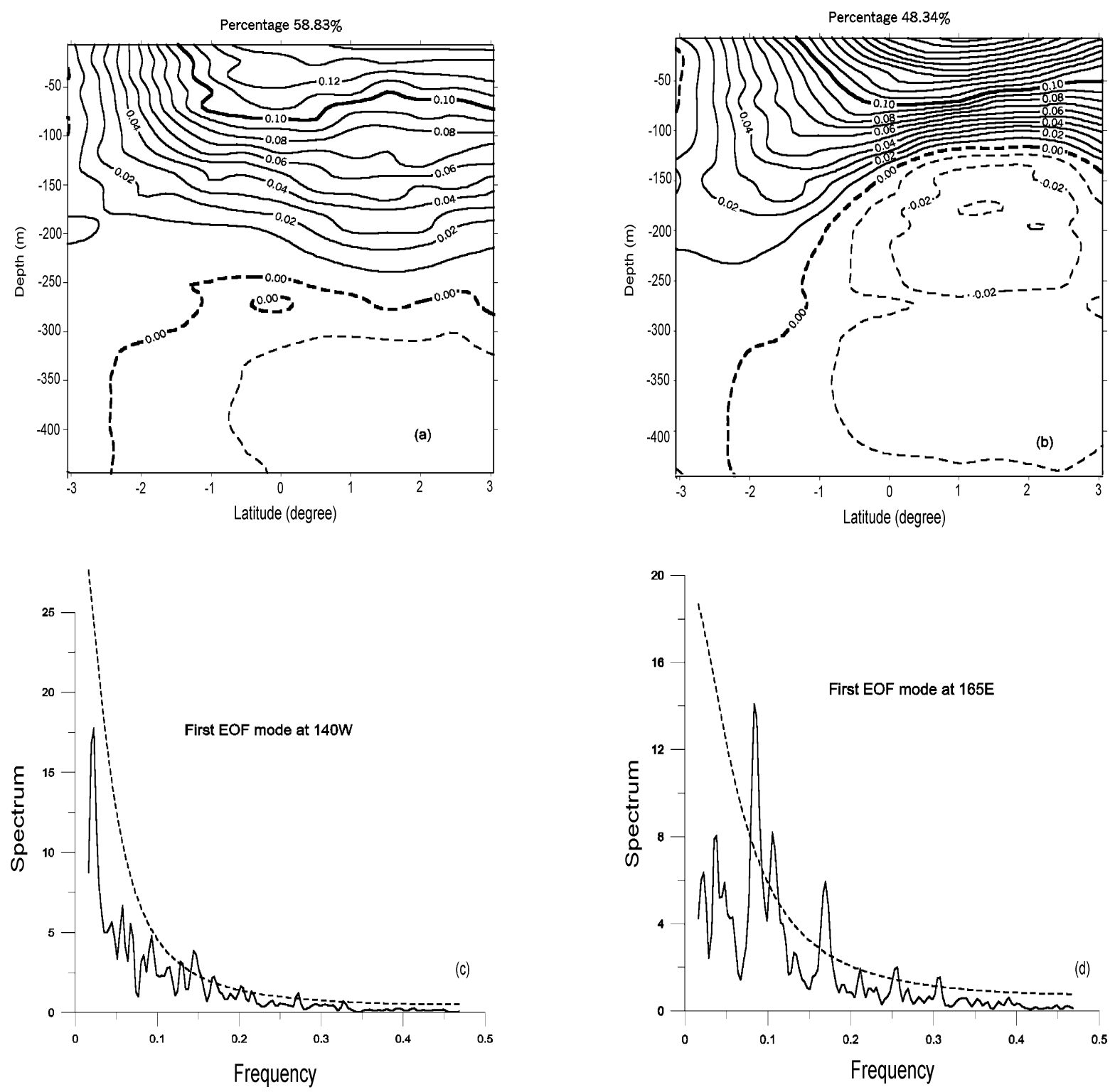

Fig. 16. The first EOF mode of the orthogonal eigenvector (upper panel) and principal component (lower panel) at longitudes $140^{\circ} \mathrm{W}$ (left) and $165^{\circ} \mathrm{E}$ (right).

the ADCP messages from buoy located at $165^{\circ} \mathrm{E}$ and near the date line.

\section{Empirical orthogonal function (EOF) analy- sis}

The EOF analysis results for the zonal current anomaly and their energy spectrum at longitudes $165^{\circ} \mathrm{E}$ and $140^{\circ} \mathrm{W}$ are presented in Fig. 16 . It can be seen that the structure of the first dominant mode is precisely compatible with the climate features revealed in Fig. 3. At $165^{\circ} \mathrm{E}$, the thickness of the positive zonal current anomaly was around 100-150 m, while at $140^{\circ} \mathrm{W}$, the upper layer thickness became nearly $300 \mathrm{~m}$. As for their amplitudes of fluctuation, there was more vibration energy at $165^{\circ} \mathrm{E}$ than at $140^{\circ} \mathrm{W}$. A correlation analysis between $150^{\circ} \mathrm{E}$ and $175^{\circ} \mathrm{E}$ showed (figure not presented) that their simultaneous correlation was 0.58 , and the correlation with $175^{\circ} \mathrm{E}$ at 1 month lag was 0.47 , with a statistical confidence above $95 \%$. The correlation between $175^{\circ} \mathrm{E}$ and $150^{\circ} \mathrm{E}$ at $1-$ month lag was only 0.21 , a relation that is quite poor. From the EOF results, it may be concluded that the dynamics of baroclinic waves in the western equatorial Pacific are different from those in the eastern $\mathrm{Pa}-$ cific. More fluctuation energy of the second baroclinic 
waves is found in the western tropical Pacific than in the eastern tropical Pacific.

Using Geosat data, Perigaud (1990) studied the sea level oscillations along the two shear fronts of the $\mathrm{Pa}-$ cific North Equatorial Countercurrent. Filtered signals of 50-90 days with the strongest amplitude were found east of $160^{\circ} \mathrm{W}$ in their study. In our EOF analysis, the strongest amplitudes of the dominant mode were found near the date line, where the significantly highest frequency of the variation had a period of more than 3 months. The baroclinic mode analysis in this paper seems more gravel than the work of Perigaud (1990).

\section{Conclusions}

The second baroclinic mode observed in the central equatorial Pacific might play an important role in the development of the El Niño event. The intraseasonal atmospheric westerly burst can influence the El Niño event through the staged atmosphere-ocean interaction mechanism. The role of the halted second "baroclinic mode" in the central equatorial Pacific as a key factor in the formation of El Niño is explained in the following staged ocean-atmosphere interaction mechanism.

The westerly bursts in boreal winter over the western equatorial Pacific generate the halted second "baroclinic mode" in the central equatorial Pacific, the increase of heat content and temperature in the upper layer of the central Pacific induces the shift of convection from over the western equatorial Pacific to the central equatorial Pacific, which leads to another westerly anomaly burst spreading over the western and central equatorial Pacific. The subsequent westerly anomaly burst generates the first "baroclinic mode" propagation to the eastern equatorial Pacific, which, at last, results in an El Niño event. The results presented here reveal that the central equatorial Pacific is a key region in detecting the possibility of the ENSO and, by analyzing currents and temperature data of TOGA-TAO (Tropical Ocean and Global Atmosphere-Tropical Atmosphere Ocean) observations in the central equatorial Pacific, a coming El Niño event may probably be predicted several months earlier.

Acknowledgments. The authors wish to thank the PMEL Laboratory for providing the TOGA-TAO observation data. Many thanks go to Professor J. A. Carton and Ms. Xianhe Cao for providing access to and support for the assimilated data of SODA. We want to express our gratitude for support from the National Natural Science Foundation of China (Grant No. 40136010) and the Education Ministry of China.

\section{REFERENCES}

Battisti, D. S., 1988: The dynamics and thermodynamics of a warming event in a coupled tropical atmosphereocean model. J. Atmos. Sci., 45, 2899-2919.

Boulanger, J. P., 2001: The Trident Pacific Model. Part 1: Simulating surface ocean currents with a linear model during the 1993-1998 TOPEX/POSEIDON period. Climate Dyn., 17, 159-173.

Carton, J. A., G. Chepurin, X. Cao, and B. S. Giese, 2000: A Simple Ocean Data Assimilation analysis of the global upper ocean 1950-1995, Part 1: Methodology. J. Phys. Oceanogr., 30 294-309.

Chen Xingyue, Wang Huijun, Xue Feng, and Zeng Qingcun, 2001: Intraseasonal Oscillation: The global coincidence and its relationship with ENSO cycle. $A d v$. Atmos. Sci., 18, 445-453.

Claire Perigaud, 1990: Sea level oscillations observed with Along the two shear fronts of the Pacific North Equatorial Countercurrent. J. Geophys. Res., 95, 72397248.

Dewitte, B., G. Reverdin, and C. Maes, 1999: Vertical structure of an OGCM simulation of the equatorial Pacific Ocean in 1985-94. J. Phys. Oceanogr., 29, 1542-1570.

Hirst, A. C., 1986: Unstable and damped equatorial modes in simple coupled ocean-atmosphere models. J. Atmos. Sci., 43, 606-630.

Lau, K. M., and P. H. Chan, 1986: The 40-50 day oscillation and the El Niño Southern Oscillation. Bull. Amer. Meteor. Soc., 67, 533-534.

Liu Qinyu, and Qin Zenghao, 1994: Coupled OceanAtmosphere characteristics in three El Nino events. Oceanologia et Limnologia Sinica, 25, 636-642. (in Chinese)

McCreary, J. P., and Z. Yu, 1992: Equatorial dynamics in a $2^{1} / 2$ layer model. Prog. Oceanogr., 29, 61-132.

McPhaden, J. M., 1999: Genesis and evolution of the 199798 El Niño. Science, 283, 950-954.

NOAA/National Weather Service, 1995: Climate diagnostics Bulletin, Monthly Series (July). USA, 38pp.

NOAA/National Weather Service, 1998: Climate diagnostics Bulletin, Monthly Series (July). USA, 43pp.

Philander, S. G. H., 1983: El Niño, Southern Oscillation phenomena. Nature, 302, 296-301.

Philander, S. G. H., 1990: El Niño, La Niña and the Southern Oscillation. Academic Press, 289pp.

Rasmusson, E. M., and T. H. Carpenter, 1982: Variations in tropical sea surface temperature and surface wind field associated with the Southern Oscillation/El Niño. Mon. Wea. Rev., 110, 354-384.

Sun, J., Q. Liu, and B. Zhu, 1997: Anomaly in tropical Pacific and its affection on El Niño. Recent Advances in Marine Science and Technology, '96, N. Saxene, Ed., Hawaii, 239-248.

Sun, J., and L. Li, 1998: Some characteristics of low frequency oscillations in the equatorial Pacific. Journal of Ocean University of Qingdao, 3, 363-369.

van Oldenborgh, G., 2000: What caused the onset of the $1997 / 98$ El Niño. Mon. Wea. Rev., 128, 2601-2607.

Zebiak, S. E., and M. A. Cane, 1987: A model ENSO/Southern Oscillation. Mon. Wea. Rev., 115, $2262-2278$ 